\title{
Rapamycin-eluting Single and Double Stenting on Serum Markers in Coronary Bifurcation Lesions
}

\author{
Jintao Wang1, Yihua Zeng2 and Hai Zhu³ \\ 1Department of Cardiology, Lanzhou University Second Hospital, China \\ ${ }^{2}$ Department of Internal Medicine, Gansu Province Hospital Rehabilitation Centre, Lanzhou, China \\ ${ }^{3}$ Department of Cardiology, Gansu Provincial Hospital, China
}

\begin{abstract}
The objective of study was to compare effects of rapamycin-eluting single and double stenting on serum markers like high sensitivity C-reactive protein (hs-CRP), tumor necrosis factor alpha (TNF- $\alpha$ ), interleukin 6 (IL-6), interleukin 8 (IL-8) and monocyte chemoattractant protein-1 (MCP-1) in patients with coronary bifurcation lesions. It was an experimental study carried out from April 2016 to July 2017. One hundred and twenty-six patients were divided into two equal groups according to different treatment regimens. Group $A$ was treated with rapamycin-eluting single stenting and group $B$ with rapamycin-eluting double stenting. Three months after operation, hs-CRP, TNF- $\alpha$, IL-6, IL-8 and MCP-1 levels in group B were lower than those in group $A(p=0.010, p<0.001, p<0.001, p<0.001$ and $p<0.001$, respectively). After one year of follow-up, rate of intrasegmental restenosis of branch vessels was higher in group $A$ than in group $B(p=0.011)$. Compared with rapamycin-eluting single stenting, rapamycin-eluting double stenting may regulate more effectively the above serum markers levels, reduce the incidence of intrasegmental restenosis of branch vessels.
\end{abstract}

Key Words: Rapamycin, Single stent, Double stent, Coronary artery bifurcation lesions.

How to cite this article: Wang J, Zeng Y, Zhu H. Rapamycin-eluting single and double stenting on serum markers in coronary bifurcation lesions. J Coll Physicians Surg Pak 2019; 30(2):222-224.

Coronary bifurcation lesion refers that stenosis of coronary artery is at the bifurcation site of the coronary artery, and stenosis of the adjacent parts of the main and/or important branches opening is equal or more than $50 \%$. Studies have shown that rapamycin-eluting stents can reduce restenosis in lesions of different morphologies. ${ }^{1}$ Inflammatory factors in blood serum such as high sensitivity C-reactive protein (hs-CRP), tumor necrosis factor alpha (TNF- $\alpha$ ), interleukin 6 (IL-6), interleukin 8 (IL-8) and monocyte chemoattractant protein-1 (MCP-1) are different kinds of bioactive substances produced mainly by the immune system, which can mediate various immune responses. The elevated levels of them are significantly related to the occurrence of various cardiovascular events. ${ }^{2}$ Single stenting and double stenting are the main coronary interventions for treatment of coronary bifurcation lesions, but choice of coronary interventions and number of stents are still controversial. 3,4

The purpose of this study was to compare effects of rapamycin-eluting single and double stenting on serum markers like hs-CRP, TNF- $\alpha, \mathrm{IL}-6, \mathrm{IL}-8$ and MCP-1 in patients with coronary bifurcation lesion.

Correspondence to: Jintao Wang, Department of Cardiology,

Lanzhou University Second Hospital, 730000, China

E-mail:xqob69@163.com

Received: November 29, 2018; Revised: May 23, 2019;

Accepted: July, 04, 2019
This experimental study was carried out at Department of Cardiology, Lanzhou University Second Hospital, China. One hundred and twenty-six patients, who underwent stent implantation, were selected as study subjects. Inclusion criteria included patients who were confirmed by coronary angiography and were in accordance with indications of different rapamycin stenting; no severe calcification; the stenosis degree of the main branch was more than $70 \%$, the stenosis degree of the initial part of branch was more than $50 \%$, the diameter of the main branch and branch vessels were more than $2.5 \mathrm{~mm}$. Patients with coronary chronic total occlusion and patients with severe allergies to rapamycin were excluded.

The patients were divided into two equal groups according to different treatment regimens. Group A was treated with rapamycin-eluting single stenting: First, the main and branch vessels were dilated by balloon, then rapamycin-eluting stent was inserted into main and branch vessels, and then balloon kissing was performed in main and branch vessels.

Group B was treated with rapamycin-eluting double stenting, using mini-crushing technique: Firstly, femoral artery puncture, insertion of artery sheath tube; and dilatation of main and branch vessels by balloon were performed. Then, according to characteristics of individual lesions, T-rapamycin-eluting stents were implanted, and terminal kissing dilatation was performed. Both 
Table I: Comparison of serum markers between two groups.

\begin{tabular}{|c|c|c|c|c|}
\hline Parameters & Time & $\begin{array}{l}\text { Group A } \\
(n=63)\end{array}$ & $\begin{array}{l}\text { Group B } \\
(n=63)\end{array}$ & $\mathrm{p}$-value \\
\hline $\mathrm{hs}-\mathrm{CRP}(\mathrm{mg} / \mathrm{L})$ & $\begin{array}{l}\text { Before treatment } \\
\text { Three months after operation }\end{array}$ & $\begin{array}{l}5.27 \pm 0.46 \\
3.35 \pm 0.79\end{array}$ & $\begin{array}{l}5.28 \pm 0.51 \\
2.96 \pm 0.87\end{array}$ & $\begin{array}{l}0.908 \\
0.010\end{array}$ \\
\hline TNF- $\alpha$ (ng/L) & $\begin{array}{l}\text { Before treatment } \\
\text { Three months after operation }\end{array}$ & $\begin{array}{l}45.16 \pm 6.02 \\
13.43 \pm 4.17\end{array}$ & $\begin{array}{l}45.77 \pm 5.25 \\
10.48 \pm 1.36 \\
\end{array}$ & $\begin{array}{c}0.804 \\
<0.001\end{array}$ \\
\hline IL-6 (ng/L) & $\begin{array}{l}\text { Before treatment } \\
\text { Three months after operation }\end{array}$ & $\begin{array}{c}38.95 \pm 16.83 \\
11.85 \pm 3.22\end{array}$ & $\begin{array}{c}39.02 \pm 17.54 \\
9.65 \pm 2.09\end{array}$ & $\begin{array}{c}0.982 \\
<0.001\end{array}$ \\
\hline IL-8 (ng/L) & $\begin{array}{l}\text { Before treatment } \\
\text { Three months after operation }\end{array}$ & $\begin{array}{l}40.34 \pm 8.19 \\
17.05 \pm 3.72 \\
\end{array}$ & $\begin{array}{l}40.92 \pm 6.35 \\
14.81 \pm 2.66 \\
\end{array}$ & $\begin{array}{c}0.658 \\
<0.001 \\
\end{array}$ \\
\hline MCP-1(ng/L) & $\begin{array}{l}\text { Before treatment } \\
\text { Three months after operation }\end{array}$ & $\begin{array}{l}625.36 \pm 45.05 \\
368.51 \pm 21.48\end{array}$ & $\begin{array}{l}626.47 \pm 48.14 \\
301.86 \pm 17.32\end{array}$ & $\begin{array}{c}0.894 \\
<0.001\end{array}$ \\
\hline
\end{tabular}

groups were used biodegradable polymer-based rapamycin-eluting stent.

Before operation and three months after operation, serum hs-CRP, TNF- $\alpha$, IL-6, IL-8 and MCP-1 were determined. The hs-CRP was measured by scattering light turbidimetry, TNF- $\alpha$ was detected by radio-immunoassay, and IL-6, IL-8 and MCP-1 were detected by enzymelinked immunosorbent assay (ELISA). After one year of follow-up, coronary angiography was performed. Revascularisation of target vessels, intrasegmental thrombosis and restenosis were observed. Collected data were analysed by SPSS 22 . Numerical data like hsCRP, TNF- $\alpha$, IL-6, IL-8 and MCP-1 were expressed as mean $\pm S D$ and independent sample t-test was used. Categorical variables like target vessel revascularisation, incidence of intrasegmental thrombosis, intrasegmental restenosis rate of branch vessels were expressed as $n$ $(\%)$, and Chi-square test was used. The $p<0.05$ showed significant difference.

Among 126 patients, 69 (54.76\%) were males and 57 $(45.24 \%)$ were females. Age ranges from 51 to 74 $(66.93 \pm 5.25)$ years. In group A, $35(55.56 \%)$ were males and $28(44.44 \%)$ were females, the age was from 52 to $74(67.27 \pm 6.02)$ years; $11(17.46 \%)$ were smokers, 6 $(9.52 \%)$ were diabetics, $4(6.35 \%)$ were hypertension patients and $5(7.94 \%)$ were hyperlipidemia patients. In group B, $33(52.38 \%)$ were males and $30(47.62 \%)$ were females, the age was from 51 to $73(65.84 \pm 4.61)$ years; $10(15.87 \%)$ were smokers, $8(12.70 \%)$ were diabetics, $3(4.76 \%)$ were hypertension patients and $4(6.35 \%)$ were hyperlipidemia patients.

Before operation, there were no significant difference in serum markers between two groups $(p=0.908,0.804$, $0.982,0.658$ and 0.894 , respectively). Three months after operation, serum hs-CRP, TNF- $\alpha$, IL-6, IL-8 and MCP-1 in group $B$ were lower than those in group $A$ $(p=0.010, p<0.001, p<0.001, p<0.001$ and $p<0.001$, respectively, Table I).

After one year of follow-up, there were two cases $(3.17 \%)$ of target vessel revascularisation in group $A$ and one case $(1.59 \%)$ in group $B$, there was no difference between two groups $(p=0.559)$. Incidence of intrasegmental thrombosis in group $A$ and group $B$ were both one case $(1.59 \%)$ each, there was no difference between two groups $(p=1.000)$. Intrasegmental restenosis rate of branch vessels in group A was 17 cases $(26.98 \%)$, which was higher than 6 cases $(9.52 \%)$ in group B $(p=0.011)$.

Studies show that rapamycin-coated stenting therapy may have important application values to treat many vascular diseases. 5 This study showed that compared with rapamycin-coated single stenting, rapamycineluting double stenting could regulate serum markers more effectively in patients, and intrasegmental restenosis rate of branched vessels after operation was lower. These results suggested that rapamycin-eluting double stenting was effective to treat this disease. The reason may be that rapamycin can inhibit release of serum markers like hs-CRP, TNF-a, IL-6, IL-8 and MCP-1; and rapamycin can interact with cell cycle regulatory proteins, inhibit cell division between G1 and S1 stages, effectively prevent the proliferation of neointima, and reduce occurrence of vascular restenosis. ${ }^{6}$ Long-term curative efficacy of rapamycin-eluting double stenting needs to be studied and analysed by extending followup time and further expanding sample size.

\section{ACKNOWLEDGEMENT:}

This work was supported by Lanzhou Science and Technology Plan Project (2017-4-61).

\section{CONFLICT OF INTEREST:}

Authors declared no conflict of interest.

\section{AUTHORS' CONTRIBUTION:}

JW: Conceived and designed the study; performed the study; wrote the manuscript.

YZ, HZ: Performed the study; wrote the manuscript.

\section{REFERENCES}

1. Pan M, de Lezo JS, Medina A, Romero M, Segura J, Pavlovic D, et al. Rapamycin-eluting stents for the treatment of bifurcated coronary lesions: A randomized comparison of a simple versus complex strategy. Am Heart J 2004; 148:857-64. 
2. Zhu X, Chen Y, Xiang L, You T, Jiao Y, Xu W, et al. The longterm prognostic significance of high-sensitive C-reactive protein to in-stent restenosis. Medicine (Baltimore) 2018; 97: e10679.

3. Karrowni W, Makki N, Dhaliwal AS, Vyas A, Blevins A, Dughman $S$, et al. Single versus double stenting for unprotected left main coronary artery bifurcation lesions: A systematic review and meta-analysis. J Invasive Cardiol 2014; 26:229-33.

4. Hariki H, Shinke T, Otake H, Shite J, Nakagawa M, Inoue T, et al.
Potential benefit of final kissing balloon inflation after single stenting for the treatment of bifurcation lesions - insights from optical coherence tomography observations. Circ J 2013; 77: 1193-201.

5. Lee $\mathrm{CH}$, Hsieh MJ, Chang SH, Chiang CL, Fan CL, Liu SJ, et al. Biodegradable cable-tie rapamycin-eluting stents. Sci Rep 2017; 7:111.

6. Haery C, Sachar R, Ellis SG. Drug-eluting stents: The beginning of the end of restenosis? Cleve Clin J Med 2004; 71:815-24.

…ํ..... 